\title{
Ambiência: espaço físico e comportamento
}

\author{
Ambience: built environment and behavior
}

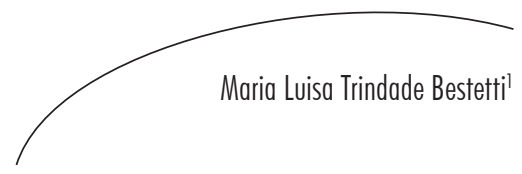

Resumo

A ambiência é um tema extremamente relevante, considerando a necessidade de estudar aspectos extrínsecos ao homem e como eles influenciam no seu envelhecimento, para que as melhores condições de espaço gerem mais qualidade no encontro entre os sujeitos. Compreender sua influência nas relações sociais possibilita a caracterização e o reconhecimento de elementos que funcionam como fortes coadjuvantes ao bem-estar subjetivo dos sujeitos que participam de quaisquer espaços, sejam públicos ou privados, de atividade ou de recolhimento. Este artigo resulta de uma revisão de literatura baseada em pesquisa teórica, buscando conjugar temas como acessibilidade e ergonomia apoiados no Desenho Universal, além de variáveis do conforto ambiental (acústica, temperatura, luminosidade, ventilação e insolação) e a humanização que efetiva o acolhimento e a produção de subjetividades. Tais elementos compõem o espaço construído, objeto da arquitetura, e seus impactos no comportamento humano, normalmente vistos de modo isolado. Esta reflexão se baseia em pesquisas de campo em andamento e permitiu gerar instrumentos de coleta de dados utilizados em entrevistas e em observações participativas.

\section{Abstract}

The ambience is an extremely relevant issue considering the need for further exploration to extrinsic human aspects and how they influence in its aging, so that the best conditions of environment generate more quality in the meeting among people. Understanding their influence on social relations enables the characterization and recognition of elements that act as strong adjuvants to subjective wellness of individuals participating in any space, whether public or private, with activity or gathering. This article results from a literature review based on theoretical research seeking to combine issues such as the composition of the built space, object of architecture, and its impact on human behavior typically seen in isolation. This reflection is based on field research now under way and enabled the generation of tools for data collection used in interviews and participant observation.

\footnotetext{
1 Curso de Gerontologia, Escola de Artes, Ciências e Humanidades. Universidade de São Paulo. São Paulo, SP, Brasil.
}

Correspondência / Correspondence

Maria Luisa Trindade Bestetti

E-mail: maria.luisa@usp.br
Palavras-chave: Arquitetura. Bem-Estar. Envelhecimento.

Key words: Architecture. Welfare. Aging. 


\section{INTRODUÇÃO}

Arquitetura é a arte de construir para atender aos desejos da sociedade, buscando seu bem-estar, conforto e segurança. Compreende espaços abertos e fechados, cobertos ou não. Com exemplos marcantes ao longo da história, os arquitetos têm desenvolvido soluções que, juntamente com os avanços tecnológicos, proporcionam condições para a constante busca desse ideal, ${ }^{1}$ demonstrando que a arquitetura dos espaços pode expressar sentimentos, além de cumprir sua função básica de abrigar. $\mathrm{O}$ ambiente onde estamos inseridos, seja ele construído ou não, emite estímulos que podem nos agradar ou desagradar, gerando sensação de desconforto se houver grande disparidade com os limites do nosso corpo. Além disso, a bagagem cultural do indivíduo determinará o que lhe é agradável ou não, pois as escolhas dependem da história de cada um.

Quando falamos em ambiência, pensamos em humanização por meio do equilíbrio de elementos que compõem os espaços, considerando fatores que permitam o protagonismo e a participação. Pressupõe o espaço como cenário onde se realizam relações sociais, políticas e econômicas de determinados grupos da sociedade, sendo uma situação construída coletivamente e incluindo as diferentes culturas e valores. $\mathrm{O}$ termo ambiência tem origem do francês "ambiance" e pode ser também traduzido como meio ambiente. Para melhor compreensão da sua abrangência, podemos afirmar que não é composto somente pelo meio material onde se vive, mas pelo efeito moral que esse meio físico induz no comportamento dos indivíduos. De acordo com o dicionário Aurélio, ${ }^{2}$ é o espaço, arquitetonicamente organizado e animado, que constitui um meio físico e psicológico, especialmente preparado para o exercício de atividades humanas.

O estudo da ambiência desejada para cada situação de espaço, em qualquer escala, traz subsídios importantes para o entendimento das condições físicas e emocionais do bem-estar subjetivo, e nisso se consideram os estímulos ao comportamento dos sujeitos inseridos nesse contexto, aprimorando seu relacionamento. É aceito o termo meio ambiente como sinônimo de ambiência, considerando-se, no entanto, que aí está inserido o meio moral, além do material. Assim sendo, um projeto arquitetônico deve ser elaborado ajustando-se todos os componentes como um sistema complexo e inter-relacionado. Além dos aspectos compositivos e programáticos, faz-se necessária uma análise das condições ambientais percebidas pelo usuário, já que é capaz de interagir com o ambiente imediato por meio dos sentidos. Assim, a percepção espacial estabelece parâmetros de orientação, conforto e qualidade ambiental, com os quais esses atores estabelecem encontros com protagonismo e participação ativa.

O meio ambiente é construído utilizandose valores objetivos como forma, função, cor, textura, ventilação, temperatura, iluminação, sonoridade e simbologia. Cada um desses valores objetivos compõe o espaço dimensionado e funcional, resultando no espaço da arquitetura ${ }^{3}$ e determinando o nível de bem-estar de seus ocupantes. Há, porém, valores subjetivos que são adquiridos culturalmente, de acordo com a experiência de vida, estabelecendo significados, positivos ou negativos, em relação aos estímulos do ambiente.

O homem é um ser social que interage com um ambiente físico e um meio social, os quais podem favorecer ou não sua adaptação ao processo de envelhecimento. ${ }^{4}$ A história que vamos compondo junto aos grupos familiar e social ao qual pertencemos suscitará as emoções, positivas ou negativas, que podem interferir no conforto e na relação que estabelecemos com o ambiente construído.

Conforto é a condição de bem-estar relativa às necessidades do indivíduo e sua inserção no ambiente imediato. Envolve não somente a eleição de critérios térmico, acústico, visual ou ainda químico, mas também o acréscimo de emoção e prazer, atribuindo-lhe um caráter 
holístico, já que o ambiente construído é um anteparo existencial, sendo abrigo para o corpo e para a alma. ${ }^{5}$

Nesse conjunto de fatores, consideramos dispositivos que permitem esta conexão, tais como a boa sinalização, seja gráfica, tátil ou sonora, que possibilite maior autonomia aos usuários de espaços coletivos, diminuindo riscos de desorientação. Também a adequação dos equipamentos complementares aos espaços, tais como assentos, apoios e dispositivos de acesso, que garanta maior produtividade com menor esforço, sem causar danos à saúde. Além disso, ao definir-se uma organização adequada para a circulação de pessoas, deve-se levar em conta a utilização do espaço territorial necessário ao homem e que influencia seu relacionamento com os outros. ${ }^{3}$

Mas ambiência não é somente espaço físico, é também encontro entre os sujeitos, propiciado pela adequação das condições físicas do lugar e pelo exercício da humanização. No campo das políticas públicas de saúde, bumanização diz respeito à transformação dos modelos de atenção e de gestão nos serviços e sistemas de saúde, indicando a necessária construção de novas relações entre usuários e trabalhadores e destes entre si, tornando-os protagonistas e corresponsáveis. ${ }^{6}$ Para Espinosa, ${ }^{7}$ o encontro de dois corpos pode aumentar ou diminuir a potência: tudo que está a serviço da opressão alimenta as paixões tristes, das quais o medo (dos castigos) e a esperança (por recompensas) são mecanismos de controle. A ideia de estar acolhido enfatiza o elemento protetor do conforto, caracterizando que todos buscam abrigos, o que ao longo das gerações teria auxiliado a sobrevivência de certos indivíduos e determinado sua vitória no processo de seleção natural. ${ }^{5}$

Masetti cita Immanuel Kant, para quem três coisas podem fortalecer o homem contra as tribulações da vida: a esperança, o sono e o riso. Também destaca que a influência dos afetos sobre o organismo foi formalmente incorporada pela Medicina, no início do século XII. O humor era um dos quatro principais fluidos do corpo, que se julgavam determinantes das condições físicas e mentais do indivíduo, segundo Hipócrates. E complementa com Aristóteles que, em 320 A.C. defendia o riso como exercício de grande valor para a saúde. 7 O humor indica desempenho mental, capacidade de enxergar situações ou pessoas de formas bastante específicas. Uma ambiência que ofereça boas condições de uso do espaço possibilita que haja bom humor dos participantes, com tendência ao surgimento do riso. Mas devemos considerar que, enquanto uma bela construção pode ocasionalmente exaltar um estado de espírito em ascensão, haverá momentos em que o local mais agradável do mundo não conseguirá expulsar nossa tristeza ou misantropia. ${ }^{8}$ A sensação corporal de prazer permite experimentar a alegria ou a felicidade, sendo missão da arquitetura criar espaços sensíveis e estimulantes que favoreçam o desenvolvimento da existência humana. ${ }^{3}$

Conforto é algo pessoal, e a razão do conforto de um pode parecer desconforto ao outro. ${ }^{5}$ Nessa premissa, se baseia a importância da ambiência nos projetos arquitetônicos e seu impacto no envelhecimento. $O$ estudo da Gerontologia abrange o processo do envelhecimento e não somente a velhice, o que torna todas as faixas etárias objetos de estudo importantes para pensarmos a longevidade como consequência de boa qualidade de vida. $\mathrm{O}$ decréscimo da capacidade física na velhice pode ser um elemento gerador da dependência, como resultado do desequilíbrio entre a experiência da limitação funcional, as demandas do ambiente e as expectativas pessoais para o desempenho nas atividades da vida diária. ${ }^{4}$ Buscar tais atributos em todos os espaços de vivência certamente contribuirá para o aperfeiçoamento dessa qualidade, em busca de melhor bem-estar.

Este estudo busca refletir sobre os elementos que definem a ambiência, considerando a falta de estudos com esta abordagem. Pela novidade do tema, faltam artigos que o fundamentem na área da Gerontologia Ambiental. 


\section{PRINCÍPIOS FUNDAMENTAIS DA AMBIÊNCIA}

Podemos definir percepção como sendo a tradução dos estímulos ambientais refletida em padrões de comportamento e com fatores selecionados por meio dos sentidos ativos de cada indivíduo. A percepção humana depende de fatores subjetivos, tais como as experiências vividas, os valores culturais do grupo social do qual o indivíduo faz parte e da seleção de códigos de referência significativos para a interpretação da realidade. Por esse motivo, podemos afirmar que a realidade de cada um é construída a partir desses filtros mentais e, portanto, é individual e única, podendo assemelhar-se conforme haja características semelhantes entre as pessoas. Assim, a percepção humana caracteriza-se por ser seletiva, absorvendo somente uma parte dos estímulos recebidos.

Também é afetiva, pois depende de a experiência acumulada ser positiva ou negativa. É capaz de formar uma ideia global de um resultado esperado, o que produz surpresas quando há novos elementos que provoquem estranhamento, justificando sua característica temporal, relacionada ao aperfeiçoamento do repertório adquirido ao longo do tempo.

Segundo Okamoto, ${ }^{3}$ podemos também classificar os sentidos em perceptivo, espacial e proxêmico. O sentido perceptivo relaciona-se aos sentidos da visão, audição, olfato, paladar e tato, usados conjuntamente ou de acordo com os estímulos mais intensos, provocando o registro de mudanças no ambiente e garantindo uma interpretação que pode causar bem-estar ou não. O ambiente físico é composto pelas pessoas e pelos equipamentos que lhes permitem desenvolver atividades, definindo o sentido espacial. O sentido proxêmico é definido como sendo relacionado às distâncias físicas que as pessoas estabelecem espontaneamente entre si no convívio social, e das variações dessas distâncias de acordo com as condições ambientais e os diversos grupos ou situações sociais e culturais em que se encontram.
O termo proxêmica foi cunhado pelo antropólogo Hall, ${ }^{9}$ em 1963, para se referir ao fenômeno da proximidade humana que se manifesta, por exemplo, no encontro social entre indivíduos ou por distâncias socialmente aceitáveis. Hall fala das variantes que essa mesma dimensão social e espacial apresenta em diferentes espaços e culturas, onde a mesma proximidade social varia. A ciência proxêmica destaca quatro categorias de espaço: íntimo, pessoal, social e público. ${ }^{3}$ Considera-se que o espaço privado é o mecanismo de controle interpessoal que regula o isolamento ou distanciamento dos outros, a fim de manter a privacidade.

A Secretaria de Atenção à Saúde, Núcleo Técnico da Política Nacional de Humanização do Ministério da Saúde, dentro do programa denominado "Humaniza SUS", criou um grupo especialmente voltado a discutir e difundir princípios relativos ao estudo da ambiência nos equipamentos de saúde. De acordo com a Cartilha de Ambiência, ${ }^{10}$ devemos considerar que o espaço visa à confortabilidade, valorizando elementos do ambiente que interagem com as pessoas e garantindo conforto aos usuários. Também possibilita a produção de subjetividades por meio do encontro de sujeitos, por meio da ação e reflexão sobre os processos de trabalho, e pode ser usado como ferramenta facilitadora desses processos, favorecendo a otimização de recursos e $\mathrm{o}$ atendimento humanizado, acolhedor e resolutivo.

De acordo com Schmid, ${ }^{5}$ a casa não pode se limitar a ser abrigo do corpo se as necessidades não se limitam ao físico. É um meio efetivo de vida que acontece no plano físico, sentimental e intelectual. A confortabilidade referida na Cartilha de Ambiência ${ }^{10}$ enfatiza os componentes que atuam como modificadores e qualificadores do espaço, estimulando a percepção ambiental. Quando utilizados com equilíbrio e harmonia, criam ambiências acolhedoras, propiciando contribuições significativas nos processos de produção. ${ }^{10}$ Destacam-se aqui aspectos relativos à morfologia, à cinestesia, à arte, à acessibilidade, à luz e à cor, mensuráveis, e à privacidade, à 
individualidade e aos valores culturais, elementos intangíveis, mas claramente percebidos quando incorporados ao espaço.

Buscam-se formas, dimensões e volumes que configuram e criam espaços, que podem ser mais ou menos agradáveis, mas sempre adequados para as pessoas. Essa morfologia deve traduzir a composição que proporcione maior bem-estar possível, especialmente dentro dos limites do uso compartilhado dos espaços coletivos de permanência transitória mais demorada ou apenas de passagem.

Além da geometria definida pela composição de formas, a percepção do espaço por meio dos movimentos, assim como das superfícies e texturas, permite traduções que também qualificam o espaço. A cinestesia é, portanto, um meio de organizar elementos de estímulo relativos à organização de fluxos e de permanência nos ambientes, visto que é definido no dicionário Aurélio como sendo a sensação que o indivíduo experimenta, conscientemente, de sua existência. ${ }^{2}$

A arte como meio de inter-relação e expressão das sensações humanas contribui para a humanização dos espaços e pode ser apresentada por meio de suas mais diversas formas de manifestação. Elementos de arte plástica, sejam eles permanentes ou transitórios, conferem ao ambiente a inserção de novas cores e formas, além de instigarem o observador ao deleite e à reflexão. Também a execução de peças musicais produz um estranhamento positivo, pois possibilitam a convergência da atenção para além da simples permanência ou transição. O edifício, por meio de detalhes construtivos, arranjos com mobiliário diferenciado ou mesmo composições de paisagismo, também proporciona a possibilidade de uma experiência gratificante e positiva, já que imprimirá elementos novos que podem ser marcantes para o uso dos espaços.

A cor estimula nossos sentidos e pode nos encorajar ao relaxamento, ao trabalho, ao divertimento ou ao movimento. Pode nos fazer sentir mais calor ou frio, alegria ou tristeza. Esse efeito psicodinâmicoé estabelecido especialmente de acordo com as experiências vividas, pois tanto o repertório imagético guardado na memória quanto a cultura do grupo social no qual estamos inseridos provocam reações, positivas ou negativas, quando há associações às cores. Tecnicamente, também podem ser adotadas para potencializar outros elementos da ambiência. Podemos compensar a falta ou minimizar o excesso de luz utilizando cores que ajudam a refletir ou absorver, ampliando o aproveitamento da luz natural e racionalizando o consumo de energia elétrica, ou criando situações de maior intimidade ou aconchego.

A privacidade diz respeito à proteção da intimidade do indivíduo, e facilita os processos de trabalho necessários aos relacionamentos profissionais. $\mathrm{O}$ aumento da interação social torna-se, também, mais espontâneo e significativo, a partir da possibilidade de encontros em ambientes que permitam escolhas. Entendendo que cada pessoa é diferente da outra, vinda de um cotidiano e espaço social específico, busca-se criar ambientes que permitam ao usuário preservar sua identidade.

Essa individualidade é reforçada pelo entendimento de que os valores culturais determinam características próprias em diferentes comunidades, que manifestam seus desejos e necessidades de acordo com suas histórias. É preciso respeitar a privacidade, autonomia e vida coletiva da comunidade em que se está atuando, construindo ambiências acolhedoras e harmônicas que contribuam para a promoção do bem-estar desse grupo social. ${ }^{10}$

\section{ASPECTOS COMPLEMENTARES AO ESTUDO DA AMBIÊNCIA}

Percebemos que a presença de pessoas com mobilidade reduzida é rara em ambientes coletivos, dadas as condições de acessibilidade, que são em geral sofríveis. Define-se deficiência como sendo a redução, limitação ou inexistência das condições de percepção das características 
do ambiente ou de mobilidade, em caráter temporário ou permanente.

Pessoa com mobilidade reduzida é aquela que, temporária ou permanentemente, tem limitada sua capacidade de relacionar-se com o meio e de utilizá-lo. Pode ser pessoa com deficiência, idosa, obesa, gestante ou fraturada, incluindo também pessoas fora do padrão antropométrico médio, além de crianças até seis anos e do idoso regular acima de 60 anos de idade. ${ }^{11}$

O Censo de 2010 apontou 23,9\% da população brasileira com pelo menos uma das deficiências investigadas (visual, auditiva, motora e mental ou intelectual), e um número ainda mais significativo de outros que possuem outras necessidades especiais. ${ }^{12}$ Faltam cuidados com espaços públicos, a começar pelas ruas e veículos de transporte, impedindo que pessoas com mobilidade reduzida se desloquem com autonomia.

Desenho Universal é um modo de concepção de espaços e produtos visando à sua utilização por amplo espectro de usuários, incluindo crianças, idosos e pessoas com restrições temporárias ou permanentes. A meta é atingir um desenho de qualidade no qual, além de requisitos estéticos, é fundamental o fácil entendimento sobre o uso (legibilidade), a segurança e o conforto para todos, dotando o espaço de qualidades que beneficiem seus usuários.

Há que se considerar seus princípios, tais como o uso equitativo, quando o desenho é utilizável por pessoas com habilidades diversas. Com o uso flexível, o desenho acomoda uma ampla faixa de preferências e habilidades. Pelo uso simples e intuitivo, torna-se de fácil compreensão, independentemente de experiência, conhecimento, habilidades de linguagem ou nível de concentração do usuário. Quando o desenho comunica a informação necessária para o usuário, independentemente de suas habilidades ou das condições do ambiente, ele se torna de fácil percepção. Também pode minimizar riscos e consequências adversas de ações acidentais ou não intencionais. Possibilita baixo esforço físico, tendo uso eficiente, confortável e com o mínimo de fadiga. Finalmente, pode prover dimensão e espaço apropriados para o acesso, o alcance, a manipulação e o uso, independentemente do tamanho do corpo, da postura ou mobilidade do usuário.

A origem do termo ergonomia vem do grego ergos, que significa trabalho, e nomos, que significa leis naturais. É a ciência que estuda a relação do homem com os equipamentos que utiliza, com vistas ao aumento da eficiência e à redução de desconfortos, aperfeiçoando seu desempenho. Antropometria é o estudo da forma e do tamanho do corpo humano. As técnicas básicas de antropometria usadas ainda hoje foram desenvolvidas no século XIX, estabelecendo medidas consistentes de uma distância determinada. Também surgiram métodos para sintetizar grupos de dados, chamando de percentil o número que é igual ou maior que um determinado percentual da população. Cabe à ergonomia transformar positivamente as condições de trabalho para as pessoas no ambiente físico (mobiliário e equipamentos), sendo fundamentais os conhecimentos específicos do Desenho Universal.

A NBR 9050-2004, ${ }^{11}$ norma técnica para acessibilidade a edificações, mobiliário, espaços e equipamentos urbanos, regulamenta as dimensões, os padrões e os dispositivos que garantem acessibilidade. Portanto, ao pensarmos em espaços novos, devemos pensálos simplesmente adequados a todos, dentro do princípio de Desenho Universal, que garante acesso de modo indiscriminado. Ou seja, adaptamos espaços já existentes para que atendam a todos, mas projetamos espaços adequados quando pensamos numa arquitetura planejada com acesso amplo e irrestrito. ${ }^{11}$ No Brasil, têm sido implantadas políticas públicas que motivem as adequações físicas, trazendo importantes benefícios aos cidadãos, quer na manutenção de suas redes sociais ou na ampliação das atividades voltadas à saúde, educação e lazer. Pensar espaços 
acessíveis é pensar na segurança e conforto de todos, evitando incidentes desagradáveis e garantindo qualidade de vida.

Acessibilidade refere-se à possibilidade de alcance, percepção e entendimento para a utilização com segurança e autonomia de edificações e equipamentos. Chama-se barreira arquitetônica qualquer elemento natural, instalado ou edificado que impeça a aproximação, transferência ou circulação no espaço ou equipamento. O Desenho Universal visa atender à maior gama de variações possíveis das características antropométricas e sensoriais da população. Os dispositivos e equipamentos especificados de acordo com a norma, aplicados e dimensionados com cuidado e bom senso, certamente garantirão maior amplitude de uso a diferentes padrões antropométricos, determinando maior bem-estar, melhor qualidade de vida e inclusão social. À medida que houver efetiva acessibilidade nas cidades, mais pessoas com mobilidade reduzida serão qualificadas para assumir os postos de trabalho disponíveis no mercado, havendo efetiva inclusão social e profissional.

Foi definido o termo restrição, pela Organização Mundial da Saúde - International Classification of Functioning, Disability and Health, em 2001, indicando o grau de dificuldade que cada indivíduo possui para realizar alguma atividade. Qualquer indivíduo pode ter restrições no desempenho de uma atividade em função de deficiência, idade avançada, condições socioculturais ou desenho do ambiente. A restrição sensorial refere-se às dificuldades na percepção das informações do meio ambiente devido a limitações nos sistemas sensoriais. A cognitiva refere-se à dificuldade no tratamento das informações recebidas (atividades mentais) ou na sua comunicação por meio de produção linguística, devido a limitações no sistema cognitivo. A restrição físico-motora refere-se ao impedimento, ou às dificuldades encontradas em relação ao desenvolvimento de atividades que dependam de força física, coordenação motora, precisão ou mobilidade. Ainda podemos considerar a restrição múltipla, que decorre da associação de mais de um tipo de restrição de natureza diversa.

O homem busca, basicamente, abrigo e proteção, mas também procura o prazer. $^{3} \mathrm{O}$ conforto ambiental possibilita as melhores condições de permanência com a máxima sensação de bem-estar, buscando a adequação dos diversos aspectos sensoriais. Analisam-se temperatura, ventilação e luminosidade, aspectos que alteram condições de habitabilidade, especialmente na questão física e na capacidade produtiva dos usuários. A quantidade e qualidade do ruído inserido dentro do espaço arquitetural também afetam essas condições, mas incidem basicamente nas questões emocionais e no comportamento advindo dessa sensação. À medida que dispomos de mais dispositivos de proteção, menos resistentes estaremos às condições climáticas naturais do meio ambiente, pois a capacidade humana para enfrentar as adversidades ambientais baseia-se no desenvolvimento de adaptações no relacionamento com o ambiente físico. Habitabilidade é um conjunto de condições que uma edificação possui e que a tornam habitável. Além do conforto ambiental, considera-se a salubridade, característica relativa à presença de germes e bactérias, que existem aos milhões em qualquer ambiente, sendo que os raios ultravioleta contidos nos raios solares têm poder germicida e ajudam na profilaxia de locais insalubres.

A temperatura no edifício é determinada pela disposição das aberturas definidas por janelas e portas, do material que constituem as paredes e dos aparelhos que produzem calor instalados nos ambientes, pois temperaturas altas produzem sensações de preguiça, de letargia e diminuem a produtividade das pessoas. A disposição dos cômodos de uma casa e também as condições climáticas da região onde a edificação está contribuem para o acúmulo ou a dissipação da umidade, sendo que ambientes muito úmidos causam sensações desagradáveis, sufoco e 
sudorese. Considera-se, ainda, que as preferências térmicas de um indivíduo são influenciadas por diversos fatores subjetivos ou individuais, destacando-se os hábitos alimentares que afetam o metabolismo, a gordura do corpo, que funciona como isolante térmico, o vestuário, que altera significativamente as trocas térmicas e o processo de aclimatação dos indivíduos, visto que as pessoas, em seus climas de permanência, tendem a produzir hábitos e alterações metabólicas que equilibram as condições térmicas adversas.

Quanto à ventilação nos ambientes, é preciso considerar que o corpo humano necessita de certa quantidade de oxigênio por hora para atender ao seu metabolismo. $\mathrm{O}$ ar ambiente, mesmo quando puro, não contém mais que $19 \%$ de oxigênio. Quando essa taxa de oxigênio cai, o organismo força a respiração, tornando-a ofegante. Quartos onde há deficiência de renovação de ar afetam a qualidade do sono. Sob a ótica do conforto térmico, os movimentos de ar aceleram as trocas de calor das pessoas com o ambiente por convecção e por evaporação. É também elemento de controle térmico dos ambientes e de salubridade. Em cada local, por fatores climáticos, topográficos e mesmo pela presença de prédios altos nas proximidades, os ventos tendem a soprar mais em determinada direção, a que chamamos de direção predominante. Alguns odores provocam sensações agradáveis, enquanto outros são indesejados e, portanto, a distribuição dos ambientes de uma residência podem permitir que os ventos predominantes tendam a carregar $\mathrm{o}$ ar de alguns cômodos para outros.

Outro aspecto importante refere-se à luminosidade, já que ambientes mal iluminados para qualquer tipo de trabalho podem causar cansaço visual. Cada tipo de trabalho exige certo grau de iluminação e, portanto, quando realizamos trabalhos minuciosos necessitamos de mais luz. A insolação adequada, considerando o efeito germicida do sol, também possibilita o melhor aproveitamento da luz natural, seja pela melhor posição de janelas ou pelo aproveitamento das superfícies refletoras no teto e paredes.
Aspectos acústicos também interferem no conforto, já que sabemos que o ruído é necessário ao ser humano, já que mesmo um ambiente excessivamente silencioso causa sensações de insegurança e até de medo. Entretanto, um ambiente ruidoso demais causa inquietação e nervosismo, assim como ruídos repetitivos, mesmo que não muito altos, causam também irritação. Os recintos refletem parcialmente as ondas sonoras que incidem sobre eles, mas o restante é absorvido; assim, os materiais utilizados nos revestimentos são responsáveis pela quantidade de absorção dessas ondas sonoras. Contra o ruído exterior, dispomos de alguns meios de proteção, tais como aumentar a distância em relação à fonte, tornando menos potentes e, portanto, menos incômodos.

Utilizar barreiras minimiza efeitos desagradáveis, sendo que podemos considerar as internas, usando revestimentos absorventes, e barreiras externas, usando superfícies refletoras ou vegetação. Também é recomendável controlar as fontes de ruídos, pelo posicionamento adequado das aberturas, quando possível. Quanto aos ruídos gerados dentro do edifício, há providências que podem contribuir para garantir o conforto: reduzir a fonte isolando-a por meio de barreiras absorventes e organizar os ambientes buscando o melhor zoneamento das atividades e reduzindo os ruídos produzidos por impactos. Quando definidos em projeto, é possível utilizar construções herméticas com isolamento acústico ou reduzir a transmissão do som pelo uso de estruturas descontínuas.

A vegetação em suas diferentes formas, seja em espécies isoladas como cobertura vegetal ou como um conjunto em área verde, influencia decisivamente no controle da qualidade ambiental, quer seja no conforto térmico, no acústico ou no luminoso. Ambiência urbana refere-se à ambiência de uma parte da cidade de acordo com seu microclima, cuja influência na paisagem altera sua configuração e a sensação de conforto percebida. ${ }^{13}$ 
O acolhimento expressa uma ação de aproximação, ou seja, uma atitude de inclusão. Os sentidos proxêmico e de prazer são, aqui, elementos fundamentais para sua efetivação, de acordo com o contexto e com a relação entre os protagonistas da ação. $\mathrm{O}$ acolhimento como postura e prática nas ações de atenção e gestão nas diversas áreas do mundo do trabalho favorecem a construção da relação de confiança e compromisso dos usuários com as equipes e os serviços oferecidos, contribuindo para a legitimação da atitude profissional. De acordo com a cartilha do Ministério da Saúde, a ambiência, enquanto espaço de encontro entre sujeitos, apresenta-se como um dispositivo que potencializa e facilita a capacidade de ação e reflexão das pessoas envolvidas nos processos de trabalho, possibilitando a produção de novas subjetividades e aumentando a eficiência funcional. ${ }^{10}$

Criar ambientes humanizados e agradáveis, sejam eles públicos ou privados, não depende somente de arranjos no espaço físico, mas também da atitude que as pessoas assumem e demonstram por meio do seu comportamento. A tarefa de tornar os lugares mais atraentes transforma-se na ação de melhorar o bem-estar de todos, aumentando a eficiência, a produtividade e melhorando a relação entre os sujeitos que participam desse processo.

\section{CONSIDERAÇÕES FINAIS}

Esta revisão de literatura permitiu a prospecção de elementos que compõem o espaço construído, objeto da Arquitetura, normalmente analisados de modo isolado. Como visto anteriormente, o Desenho Universal permite o melhor desempenho com o menor esforço para todas as pessoas, mesmo aquelas com mobilidade reduzida. Além disso, compreender as variáveis do conforto ambiental como os impactos de ruídos, variações de temperatura e luminosidade, benefícios de ventilação e insolação adequadas, comprova que cada organismo apresenta especificidades que definem limites de bemestar que podem ser controlados em espaços construídos bem planejados.

A humanização possibilita o acolhimento $\mathrm{e}$ a produção de subjetividades e será mais efetiva com arranjos espaciais que estimulem encontros prazerosos e respeitem os limites territoriais aceitos socialmente. A conjugação desses temas possibilitou compreender onde há interrelacionamentos para os quais determinadas soluções arquitetônicas potencializam situações de conforto. Porém, a percepção sensorial é particular de cada indivíduo e, especialmente considerando a experiência de vida das pessoas idosas, ficou provado que coletar dados nesse sentido permitiria analisar a percepção de conforto em espaços construídos ocupados por esses sujeitos.

Esta reflexão se baseia em pesquisas de campo ora em andamento e possibilitou a geração de instrumentos de coleta de dados, utilizados em entrevistas e em observações participativas. A primeira delas, realizada no Centro de SaúdeEscola Butantã, permitiu comparar resultados antes e depois de uma reforma e adequação do espaço entre 2011 e 2013, por meio de entrevistas com perguntas objetivas sobre a percepção de conforto de usuários maduros, cujos resultados estão em fase de publicação.

Aguarda-se atualmente a liberação do Comitê de Ética em Pesquisa para a coleta de dados em casas de acolhida de São Paulo, instituições de parceria público-privada para permanência provisória de idosos em vulnerabilidade social, política pública do governo municipal. Pretende-se levantar as impressões de idosos em relação aos locais de moradia provisória e o entorno imediato, especialmente locais de encontro como praças e esquinas. Portanto, a pesquisa teórica aqui apresentada permitiu o desenvolvimento de instrumentos que podem ainda ser aperfeiçoados, sendo possível a busca de validação quando estiver demonstrada sua efetiva aplicabilidade. 


\section{REFERÊNCIAS}

1. Bestetti MLT. Habitação para Idosos: o trabalho do arquiteto, arquitetura e cidade [tese]: São Paulo: FAU USP; 2006

2. Ferreira ABH. Dicionário Aurélio da Língua Portuguesa. São Paulo: Cultura; 2004. Ambiência;

3. Okamoto J. Percepção Ambiental e Comportamento: visão Holística da Percepção Ambiental na Arquitetura e na Comunicação. São Paulo: Mackenzie; 2002.

4. Diogo MJD. O Envelhecimento da Pessoa Portadora de Necessidades Especiais. In: Diogo MJD, Neri AL. Saúde e Qualidade de Vida na Velhice. 2. ed. Cachioni M, organizador. Campinas: Alínea; 2006. p. 75-86

5. Schmid AL. A Ideia de Conforto. Reflexões sobre o ambiente construído. Curitiba: Pacto Ambiental; 2005.

6. Barros RDB, Pereira EHP. Dicionário da Educação Profissional em Saúde [Internet]. Rio de Janeiro: Observatório dos Técnicos em Saúde da Fiocruz, EPSJV; 2006 [acesso em Jul 2009]. Humanização. Disponível em: www.slab.uff.br/textos/texto91.pdf

7. Masetti M. Boas Misturas: a ética da alegria no contexto hospitalar. São Paulo: Palas Athena; 2003.
8. Botton A. A Arquitetura da Felicidade. Rio de Janeiro: Rocco; 2007.

9. Hall ET. A Dimensão Oculta. São Paulo: Martins Fontes; 2005.

10. Ministério da Saúde, Secretaria de Atenção à Saúde. Cartilha de Ambiência [Internet]. Brasília, DF; 2006 [acesso em Jul 2009]. Disponível em: www.saude.gov. $\mathrm{br} /$ humanizasus

11. Associação Brasileira de Normas Técnicas. NBR 9050: Norma Técnica para acessibilidade a edificações, mobiliário, espaços e equipamentos urbanos. Brasília, DF: ABNT; 2004.

12. Brasil. Secretaria de Direitos Humanos da Presidência da República, Secretaria Nacional de Promoção dos Direitos da Pessoa com Deficiência. Cartilha do Censo 2010: pessoas com deficiência [Internet]. Brasília, DF; 2012 [acesso em Nov 2012]. Disponível em: http://www.pessoacomdeficiencia.gov.br/app/ sites/default/files/publicacoes/cartilha-censo-2010pessoas-com-deficienciareduzido.pdf

13. Mascaró L, Mascaró J. Ambiência Urbana. 3. ed. Porto Alegre: Masquatro; 2009. 